\title{
The hCMEC/D3 cell line as a model of the human blood brain barrier
}

\author{
Babette Weksler ${ }^{1}$, Ignacio A Romero ${ }^{2}$ and Pierre-Olivier Couraud ${ }^{3,4,5^{*}}$
}

\begin{abstract}
Since the first attempts in the 1970s to isolate cerebral microvessel endothelial cells (CECS) in order to model the blood-brain barrier (BBB) in vitro, the need for a human BBB model that closely mimics the in vivo phenotype and is reproducible and easy to grow, has been widely recognized by cerebrovascular researchers in both academia and industry. While primary human CECs would ideally be the model of choice, the paucity of available fresh human cerebral tissue makes wide-scale studies impractical. The brain microvascular endothelial cell line hCMEC/D3 represents one such model of the human BBB that can be easily grown and is amenable to cellular and molecular studies on pathological and drug transport mechanisms with relevance to the central nervous system (CNS). Indeed, since the development of this cell line in 2005 over 100 studies on different aspects of cerebral endothelial biology and pharmacology have been published. Here we review the suitability of this cell line as a human BBB model for pathogenic and drug transport studies and we critically consider its advantages and limitations.
\end{abstract}

Keywords: Blood-brain barrier, Immortalized cell line, Brain endothelium, In vitro model

\section{Review}

Derivation and selection of hCMEC/D3 cells

The hCMEC/D3 cell line was derived from human temporal lobe microvessels isolated from tissue excised during surgery for control of epilepsy. The primary isolate was enriched in CECs. In the first passage, cells were sequentially immortalized by lentiviral vector transduction with the catalytic subunit of human telomerase (hTERT) and SV40 large T antigen, following which CEC were selectively isolated by limited dilution cloning, and clones were extensively characterized for brain endothelial phenotype [1].

The hCMEC/D3 cells form a contact-inhibited monolayer of elongated cells on collagen type I or type IV. They do not show adhesion-independent growth in soft agar but form capillary structures in Matrigel, a characteristic property of cultured endothelium. They were reported to have an apparently normal diploid human karyotype [1], although a high-resolution multicolor fluorescence in situ hybridization (FISH) approach revealed a more complex karyotype at high passages than initially thought [2]. In addition, they stain positively for

\footnotetext{
* Correspondence: pierre-olivier.couraud@inserm.fr

${ }^{3}$ Inserm, U1016, Institut Cochin, Paris, France

${ }^{4}$ CNRS, UMR8104, Paris, France

Full list of author information is available at the end of the article
}

endothelial markers including CD34, CD31, CD40, CD105, CD144 (VE-cadherin) and von Willebrand factor, but not for CD36, which is absent from brain endothelium. They maintain stable growth and endothelial marker characteristics, at least until the $35^{\text {th }}$ passage.

\section{The 'physical barrier' in hCMEC/D3 cells}

Optimal culture conditions are essential for a brain endothelial phenotype with mature adherens junction (AJ) and tight junction (TJ) protein expression and a strong permeability barrier function. Full differentiation associated with expression of CEC markers like TJ proteins requires cellular quiescence, achieved either by removal of key growth factors and/or by exposing cells to shear stress under flow (see below). Substrates for cell growth may also contribute to differentiation. For example, hCMEC/D3 monolayers display five-fold higher concentrations of $\mathrm{TJ}$ proteins on transwell filters than on plastic coverslips; in the same vein, we shall describe below the hCMEC/D3 response to activation of Wnt/ $\beta$ - catenin signaling, known to induce BBB formation during fetal development.

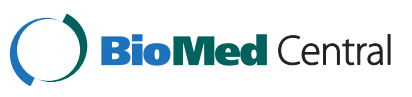




\section{Expression of junctional proteins}

In the context of endothelial cell junctions, hCMEC/D3 cells are positive for junction-associated Ig-like proteins such as PECAM-1 and JAM-A, for AJ and TJ structural proteins such as VE-cadherin, claudin-3,-5 and occludin as well as for scaffolding proteins such as beta catenin and zonula occludens ( $\mathrm{ZO}$ )-proteins- 1 and 2 [1,3]. The small G-protein Goi2, suggested as a TJ-associated protein, was indeed identified as a partner of claudin- 5 and its presence was necessary for TJ formation in hCMEC/ D3 cells [4]. Expression of claudins and occludin at intercellular junctions is best observed when the cells are confluent, treated with anti-inflammatory steroids such as hydrocortisone, anti-oxidant agents such as resveratrol, or the $\mathrm{Wnt} / \beta$-catenin signaling activator, lithium chloride $(\mathrm{LiCl})$. The $\mathrm{Wnt} / \beta$-catenin pathway acts in hCMEC/D3 cells to induce/enhance the BBB phenotype by increasing expression of claudins as demonstrated in primary mouse CECs [5]. Similarly, all growth factors, particularly vascular endothelial growth factor (VEGF), should be removed from the culture medium with the exception of basic fibroblast growth factor (bFGF) to enhance expression of junctional proteins. The hCMEC/ D3 cells express other newly identified junctional proteins such as annexins- 1 and -2, which also appear to be important for maintenance of TJ integrity [6].

Comparison of transcriptional profiles of hCMEC/D3 cells and primary human CEC with freshly isolated mouse CEC confirmed the expression by hCMEC/D3 cells of a substantial number of genes expressed by brain endothelium, but showed lower expression of claudin-5, occludin, JAM-2, glut-1 and the insulin receptor [7]. The authors concluded that in order to attain a mature brain endothelial phenotype, other cell types present in the neurovascular unit (e.g. astrocytes, pericytes) regulate gene expression by CEC, suggesting that a more complex in vitro model might be required to fully mimic the BBB. Alternatively, in line with the aforementioned differentiating action of the $\mathrm{Wnt} / \beta$-catenin pathway, complementing the hCMEC/D3 culture medium with astrocyte- and/or pericyte-derived soluble factors might be sufficient for further differentiation towards a BBB phenotype.

\section{Restricted permeability to paracellular tracers}

Monolayers of hCMEC/D3 show restricted permeability to lucifer yellow (LY: a low molecular weight paracellular diffusion marker) and to many hydrophobic and hydrophilic low molecular weight drugs which correlate with in vivo permeability coefficients as demonstrated by Weksler et al [1] and confirmed by Poller et al [8]. They also show a restricted permeability to low and high molecular weight dextrans that is similar to primary CECs and lower than non-cerebral endothelium (e.g. human umbilical vein endothelial cells, HUVECs), particularly under conditions of flow [9]. Indeed, for compounds of MW $>4000$, the permeability profile is very similar to that of bovine and porcine CECs, hitherto the best characterized in vitro BBB models. As discussed above for TJ protein expression, the permeability barrier function is maximized in the presence of $\mathrm{LiCl}$ and corticosteroids (or resveratrol): in these conditions, the permeability coefficient (Pe) for LY, is: $1.55+/-0.1610^{-3} \mathrm{~cm} / \mathrm{min}$. For comparison, Pe values for $4 \mathrm{kDa}$ - and $70 \mathrm{kDa}$-dextrans are: $0.72+/-0.0710^{-3} \mathrm{~cm} / \mathrm{min}$ and $0.09+/-0.0110^{-3} \mathrm{~cm} / \mathrm{min}$, respectively.

Conversely, stress conditions and extracellular stimuli have been shown to increase paracellular permeability of hCMEC/D3 cells via signaling pathways such as JNK, PKC or NFKB. These include mannitol treatment, oxygen and glucose deprivation (OGD) and pro-inflammatory cytokines such as TNF $\alpha$ and chemokines such as CCL2. Cowan et al [10] examined the effects of OGD under static conditions in hCMEC/D3 cells. They observed a reversible increase in monolayer permeability to dextran after $1 \mathrm{~h}$ of OGD without cytotoxicity, but permanent changes in monolayer permeability and marked cytotoxicity after $12-24 \mathrm{~h}$. The acute permeability changes involved the generation of nitric oxide and could be prevented by blocking inducible nitric oxide synthase. Other studies have demonstrated that cytokines/chemokines increase the paracellular permeability of hCMEC/D3 cells to dextrans via different mechanisms [11]. With proinflammatory stimuli, ZO-1, occludin and claudin-5 expression levels are decreased [11,12], whereas JAM-A translocates away from tight junctions, without any expression changes [13]. The chemokine CCL2, which is elevated during CNS inflammation and is associated with endothelial dysfunction, transiently induces Src-dependent disruption of hCMEC/D3 AJs, translocation of $\beta$-catenin from the AJ to PECAM-1, and increases surface localization of PECAM-1 [14].

In brief, these studies illustrate the usefulness of the hCMEC/D3 model for unraveling the regulatory mechanisms of junctional integrity and $\mathrm{BBB}$ permeability in pathological conditions (for a review see [15]).

\section{Transendothelial electrical resistance (TEER)}

Although the TEER of human cerebral microvessels has not been directly determined, it is widely accepted that mammalian systems such as the rat show high TEER values well above $1,000 \Omega \cdot \mathrm{cm}^{2}$, a characteristic of the $\mathrm{BBB}$ in vivo [16]. However, TEER values above 1,000 $\Omega \cdot \mathrm{cm}^{2}$ are difficult to achieve in cultured CEC in vitro and this is particularly true for cell lines compared to primary cultures. Under static culture conditions, hCMEC/D3 monolayers develop only a low to mediumlevel TEER (around 30-50 $\Omega \cdot \mathrm{cm}^{2}$ ) in various reports. Interestingly, higher TEER values close to $300 \Omega \cdot \mathrm{cm}^{2}$, 
were observed in the presence of hydrocortisone, probably due to the modulatory activity of corticosteroids on the expression of $\mathrm{TJ}$ proteins such as occludin and claudin-5 [12]. Another strategy targeted at increasing TEER values in hCMEC/D3 cells has involved co-culture with other cell types forming the neurovascular unit, as suggested above. In a recent paper, co-culture of hCMEC/D3 cells with astrocytes from different brain regions evoked a significant TEER increase from 30 to over $60 \Omega \cdot \mathrm{cm}^{2}$ [17]. In both monocultures and cocultures of hCMEC/D3 with astrocytes, TEER values increased from baseline over an interval of 5 days, presumably due to $\mathrm{TJ}$ maturation with time. By far the most promising method to increase hCMEC/D3 cell TEER values has been exposure to flow-based shear stress. Indeed, in hCMEC/D3 monolayers subjected to pulsatile flow after seeding in a capillary cartridge system, the TEER was reported to rise to $1000-1200 \Omega \cdot \mathrm{cm}^{2}$, then to rapidly drop following flow cessation [8]. Co-culture with astrocytes did not induce any further increases in TEER values in this flow-based model suggesting that, at least in vitro, shear stress may be a more critical factor in inducing a mature barrier phenotype than interactions with other cell types.

\section{The 'transport' barrier in hCMEC/D3 cells}

Efflux and trans-cellular transport systems expressed by CECs are key factors for studying and predicting interactions of drugs at the BBB; an adequate pattern of transporter expression thus constitutes a prerequisite for suitable in vitro human BBB models.

\section{Expression, function and regulation of $A B C$ transporters}

hCMEC/D3 cells express functional efflux transporters (known as ABC transporters because they contain ATPbinding cassette(s) for active transport), typical for brain endothelium, as observed in freshly isolated human brain microvessels: these include P-glycoprotein (P-gp or MDR1 or $A B C B 1)$, breast cancer resistance protein (BCRP or ABCG2), and multidrug resistance-associated proteins (MRP) -4 and -5 (or ABCC4 and 5) [18]. In addition, hCMEC/D3 cells express MRP-1, as previously reported with primary human brain endothelial cells in culture, strongly suggesting that in vitro culturing may non-physiologically induce the expression of this gene [18]. Protein expression of P-gp/MDR1, MRP4, BCRP by hCMEC/D3 cells (grown on collagen-coated dishes) was further assessed by quantitative proteomic analysis [19], whereas no expression of P-gp/MDR1 was detected in HUVECs, used as reference non-brain EC. Interestingly, expression levels of P-gp, BCRP and MRP4 were similar in hCMEC/D3 cells and in isolated human brain microvessels [19]. Moreover, these key transporters are functional in hCMEC/D3 cells as efflux transporter inhibition studies invariably leads to elevated intracellular levels of their substrates $[1,8,18]$. In addition, P-gp expression is polarized to the apical membrane as previously demonstrated in situ in human brain microvessels and appears to be stable for at least 40 passages [20].

$\mathrm{ABC}$ transporter activity and/or expression levels may be modulated by extracellular stimuli. For example, Poller et al [21] noted that P-gp activity was not altered by TNF- $\alpha$ treatment, although P-gp expression levels increased after treatment. However, it is noteworthy that apparent increases in P-gp expression have been found in some cases to be due to selection of high Pgpexpressing hCMEC/D3 cells, for example, after exposure to potentially cytotoxic agents, and so may not reflect real increases in P-gp expression [22]. Substrates for P-gp can increase its level of expression and activity as demonstrated in hCMEC/D3 cells exposed to the HIV-1 protease inhibitors ritonavir and atazanavir, both substrates for P-gp. Inhibition of P-gp (but not of MRP-1) increased transport of these protease inhibitors. These drugs bind the xenobiotic receptor PXR which likely acts as a transcription factor for P-gp [23]. Concern about P-gp up-regulation during long-term administration of antiretroviral therapy, thus possibly blocking brain entry of these protease inhibitors (as well as of other therapeutic drugs) suggests that the hCMEC/D3 model may prove useful in designing newer antiretroviral therapies that use other means of crossing the BBB. Of interest, HIV-1 Tat can also lead to up-regulation of P-gp expression and hence contribute to decreased entry of antiretroviral therapy into the CNS [24].

In contrast to P-gp, BCRP expression and activity are decreased by inflammatory cytokines, in particular IL-1 $\beta$ and TNF $\alpha$ [21]. Conversely, agonists of the peroxisome proliferator-activated receptor alpha (PPAR $\alpha)$ upregulate BCRP in hCMEC/D3 cells, and can significantly decrease accumulation of drugs that are BCRP substrates (e.g. mitoxantrone). PPAR $\alpha$ antagonists downregulate $\mathrm{BCRP}$ in these CECs [25] suggesting new targeting strategies for either improving drug brain bioavailability or increasing neuroprotection. Along the same lines, BCRP was shown, using hCMEC/D3 cells, to mediate the transport of nifurtimox, an antitrypanosomal drug [26]. These observations indicate that BCRP inhibitors potentially could improve the activity of anti-trypanosomal drugs and confirm that the hCMEC/ D3 model is appropriate to test novel drugs.

\section{Influx transporters of the solute carrier family and receptor-mediated transcytosis}

Brain endothelium is known to express a large number of membrane receptors and transporters that specifically control the blood-to-brain transport of nutrients, including insulin, transferrin and LDL receptors as well as glucose, 
amino-acids and organic ion transporters, all members of the solute carrier family (SLC) of transporters. Accordingly, hCMEC/D3 cells were tested for expression of these receptors and transporters by immunochemical analysis, RTPCR and/or quantitative proteomic analysis. First, they were shown to express at a high level the glucose transporter Glut-1 and the transferrin receptor. Indeed, Glut-1 expression was found by quantitative proteomic analysis to be 15-fold higher in hCMEC/D3 cells than in HUVECs and similar to that of human brain microvessels [19]. Influx transporters such as the cation transporter OCT-1, and to a lesser extent OCT-2 and -3 are expressed and functional in hCMEC/D3 cells. OCT-1 is responsible for CEC uptake of the antiepileptic drug lamotrigine, a process blocked by the selective inhibitor prazosin [27]. Also, hCMEC/D3 cells express the neutral and cationic amino acid transporter $\left(\mathrm{ATB}^{0+}{ }^{+}\right)$, which may be involved in the brain uptake of the anti-influenza compounds amantadine and rimantadine [28]. In addition, Carl et al [29] reported the expression by hCMEC/D3 cells of the monocarboxylate transporters SLC16A1 and SLC16A3 (MCT1 and MCT3), while little or no expression of SLC16A2 (MCT2) was noted. In agreement with these data, a high level of SLC16A1 expression at the protein level was detected by quantitative proteomic analysis of hCMEC/D3 cell extracts [19]. Regarding the proton-coupled oligopeptide transporter superfamily (POT, SLC15A) transporters, Carl et al also reported that hCMEC/D3 cells express both hPHT1 and hPHT2, while little to no expression of either hPepT1 or hPepT2 was observed, in line with previous data in the human BBB in vivo [29].

\section{The 'metabolic' barrier in hCMEC/D3 cells}

The activity of drug-metabolizing enzymes, especially phase 1 cytochromes P450 (CYPs), might also indirectly control the cerebral uptake of compounds from the blood [30]. The aryl hydrocarbon nuclear receptor (AhR) was detected in hCMEC/D3 cells and dioxin (a ligand of AhR) treatment increased cytochromes P450 CYP1A1 and CYP1B1 over 20-fold [18]. Interestingly, CYP1B1 was previously identified as the major CYP in freshly isolated human brain microvessels [31], suggesting that the hCMEC/D3 model may be well adapted for further studies regarding the regulatory mechanisms of CYP1B1 expression by brain endothelium.

\section{Drug vectorization and trans-cellular transport}

Numerous studies of liposomes and nanoparticles as vehicles for crossing the BBB while avoiding efflux transporters have utilized hCMEC/D3 cells. For example, Chattopadhyay et al [32] showed that solid lipid nanoparticles encapsulating atazanavir can circumvent P-gp efflux activity that usually limits uptake of the drug. Markoutsa et al [33] tested immunoliposomes bearing both a monoclonal antibody to the transferrin receptor (OX-28) and another isotype-matched monoclonal antibody linked to the lipid particles via a biotin-streptavidin technique, and showed that these structures were well taken up and transcytosed. These authors concluded that the hCMEC/D3 model was useful for particle transport studies. More recently, a combination of LDL receptor-targeted liposome-encapsulated doxorubicin and statins, known to increase LDL receptor expression, was shown to increase the drug delivery across hCMEC/ D3 monolayers [34], suggesting a new concept of drug delivery to the brain. The toxicity of gold nanoparticles was evaluated in hCMEC/D3 compared to epithelial cells [35]. Sodium citrate on the particle surface but not particle size contributed to impaired viability and proliferation of endothelial cells, which internalized fewer nanoparticles than epithelial cells.

Single chain camelid antibody VHH fragments with anti-glial fibrillary protein (GFP) activity as well as fusion protein $\mathrm{VHH}-\mathrm{GFP}$ were able to cross hCMEC/D3 monolayers as "fluobodies" [36]. Indeed, the same VHH crossed the BBB in vivo in mice and localized to astrocytes, showing for the first time that an antibody was efficiently able to penetrate the BBB and target resident cells in the brain.

\section{Interactions of immune cells with hCMEC/D3 cells}

Although the CNS was originally considered an "immuneprivileged site" because of the presence of the BBB and the apparent absence of lymphatic drainage, it is now well recognized that activated lymphocytes and monocytes do infiltrate the CNS by crossing the BBB and that neuroimmune diseases such as multiple sclerosis are characterized by massive perivascular infiltrates around brain microvessels. The hCMEC/D3 cell line provides a useful model for deciphering the modes of interactions between human brain endothelium and activated immune cells.

\section{Response of hCMEC/D3 cells to inflammatory mediators}

The hCMEC/D3 cells respond to inflammatory stimuli by increasing paracellular permeability to tracers (see previous section) and are able to support adhesion and migration of leukocytes by increased expression of adhesion proteins like ICAM-1 and VCAM-1 [1]. They express functional cytokine and chemokine receptors such as TNFR1 and 2, IFNGR1 and CXCR1-5 and CCR3-6 $[1,37]$. Indeed, Fasler-Kan et al [38] demonstrated TNF $\alpha$ activation of $\mathrm{NF} \mathrm{B}$ signaling, whereas interferon gamma (IFN $\gamma$ induced activation of JAK/STAT signaling pathways, and upregulated MHC Class I. In addition, secretion of chemokines by CECs may be an additional mechanism for modulating leukocyte extravasation. Furthermore, hCMEC/D3 cells secrete chemokines in a similar fashion to primary human brain endothelium 
both under basal conditions (CCL2 and CXCL8) or following stimulation by cytokines (CCL5, CXCL10, CX3CL1 or fractalkine) $[39,40]$.

\section{Leukocyte adhesion to and transmigration across hCMEC/} D3 cells

Monocytes adhere to activated hCMEC/D3 cells and migrate across the monolayer. The interaction between human monocytes and hCMEC/D3 cells involves the generation of reactive oxygen species (ROS), release of tissue-plasminogen activator (tPA) from the endothelial cells and a subsequent increase in permeability of the endothelial monolayer to large molecules (>150 kDa). Degradation of occludin appears to mediate the opening of endothelial-endothelial TJs [41]. Blocking the ERK1/2 pathway can partly reverse the monocyte-induced opening of monolayer TJs and impede occludin degradation. The same mechanism as demonstrated in the hCMEC/ D3 model underlies brain changes in experimental autoimmune encephalomyelitis in the rat, a model of multiple sclerosis, as well as in rat monocytes and rat brain endothelial cells in vitro, suggesting that it is a generalized mechanism and may be pertinent in multiple sclerosis pathology. The same authors recently reported that a modulator of the sphingosine-1-phosphate (S1P) receptor, known to reduce inflammatory lesions in multiple sclerosis (FTY720P or Gilenya ${ }^{\circledR}$ ), actually maintains hCMEC/D3 cells in a state of immune quiescence associated with decreased transmigration of monocytes [42]. This result further validates the hCMEC/D3 model for investigating the regulatory mechanisms of inflammation at the $\mathrm{BBB}$.

Monocyte adhesion to hCMEC/D3 cells is enhanced by endothelial treatment with TNF $\alpha$ or IFN $\gamma$ and can be inhibited by antibodies to the integrin VLA-4. A role for the junction-associated prion protein $\mathrm{PrP}^{\mathrm{C}}$ in monocyte transmigration through brain endothelial cells was demonstrated with hCMEC/D3 cells, using either the U937 monocytic cell line or fresh primary blood monocytes: antibodies to the prion protein inhibited monocyte transmigration across the endothelial layer, whereas anti-PECAM 1 antibodies had no effect [43]. This inhibition was also observed with mouse primary brain EC and with a rat brain endothelial cell line, suggesting, as above, a mechanism common to brain endothelium from several species.

Bahbouhi et al [44] used hCMEC/D3 cells as a BBB model to compare adhesion and transmigration across CEC by peripheral blood mononuclear cells (PMBC) or purified $\mathrm{T}$ cells from multiple sclerosis patients versus PBMC or $\mathrm{T}$ cells from healthy individuals. They observed that PBMC migration is dependent on PSGL-1 and LFA-1 present on the PBMC. Both CD4+ and CD8+ $\mathrm{T}$ cells utilize these ligands to adhere to brain endothelium via P-selectin and VLA-4, respectively, and adherence can be blocked by anti-ligand antibodies. In multiple sclerosis, the frequency of CD4+ $\mathrm{T}$ cells that are PSGL-1+ is significantly greater than in healthy individuals; CD8+ cell populations were similar in both MS patients and controls. Transmigration of PBMC from multiple sclerosis individuals was enhanced across both resting and TNF $\alpha$-activated hCMEC/D3 cells. The absolute transmigration was much greater across TNF $\alpha$-activated hCMEC/D3 cells. Interestingly, PMBC from individuals treated with IFN $\beta$ a widely used first-line treatment of multiple sclerosis) had lower rates of transmigration and demonstrated lower LFA-1 levels.

Whether human neutrophils induce permeability changes in brain endothelium was studied by Joice et al [45] using hCMEC/D3 monolayers. This study was undertaken to understand whether neutrophil accumulation contributes to vasogenic edema in stroke. Untreated neutrophils applied to the hCMEC/D3 monolayers for 30 min actually decreased baseline permeability to low molecular weight $(4 \mathrm{kDa})$ dextran by $53 \%$, whereas neutrophils preactivated with TNFo, LTB4 or PMA (treatments that induced marked release of ROS) had no effect on baseline permeability. The authors then showed, in rats injected intracerebrally with human neutrophils, that very similar changes in brain vascular edema were seen. The authors concluded that the hCMEC/D3 model was useful in evaluating potential contributions to vasogenic edema.

\section{The hCMEC/D3 model for investigating Host- Pathogen Interactions}

The hCMEC/D3 cell line has been widely used to model brain endothelium for investigating the molecular mechanisms of its interaction with and response to multiple human pathogens (viruses, fungi, bacteria and parasites) known to affect the CNS. Below are mentioned some of the most exciting results reported in this field.

\section{Retroviruses}

Studies related to retroviral infection have concerned two pathogens, HTLV-1 and HIV-1. HTLV-1 infects hCMEC/D3 cells via their receptors for viral entry, Glut-1 and neuropilin-1, an observation that has been confirmed in situ in necropsy material from patients with TSP/HAM (tropical spastic paraparesis/human T-lymphotropic virus type-I-associated myelopathy) [3]. CEC infection leads to increases in paracellular permeability and TJ disorganization, probably via expression of the viral protein Tax. An additional mechanism leading to BBB disruption is via secretion of TNF $\alpha$ and IL1 $\alpha$ by HTLV-1 infected T cells [46].

In the context of HIV-1, studies on hCMEC/D3 cells have focused on 1) mechanistic studies on HIV-1- 
induced BBB breakdown or 2) a model to investigate effects of anti-HIV therapeutics, particularly protease inhibitors, on BBB function (see previous section). For mechanistic studies, it has been demonstrated that HIV1 and/or Tat protein induces disruption of claudin-5 and increases permeability of hCMEC/D3 cells in a similar fashion to effects on primary rodent BECs [47]. Tatinduced delocalization of $\mathrm{ZO}-1$ from the membrane into the nucleus is mediated by Rho signaling and CREB [48]. In addition, Tat induces hCMEC/D3 cells into an activated inflammatory state by inducing increased expression of IL-1 $\beta$, E-selectin, CCL-2, and IL-6 [49], an effect that is attenuated by PPAR $\alpha$ and PPAR $\gamma$ agonists [50] via matrix metalloproteases [51]. As a result, HIV-1infected monocytes, or Tat protein itself, have been shown to increase ICAM-1 expression and to favor transmigration of the infected monocytes across hCMEC/D3 cells by a mechanism that involved NFKBinduced release of MMP-9 [52].

HIV Tat also induces amyloid beta $(A \beta)$ peptide accumulation in hCMEC/D3 cells which may contribute to its effect on $\mathrm{BBB}$ function [53]. $\mathrm{A} \beta$ accumulation and Tat-induced barrier dysfunction are lipid raft- and caveolae-dependent and involve caveolae-associated Ras signaling $[54,55]$. As mentioned above, Tat can also lead to up-regulation of P-gp expression and hence contribute to decreased entry of antiretroviral therapy into the brain [24].

\section{Cryptococcus}

Adhesion to and penetration across a monolayer of hCMEC/D3 cells by the fungal pathogen Cryptococcus neoformans was demonstrated by $\mathrm{Vu}$ et al [56], who found that a large polysaccharide capsule on the fungus plus CD44, the hyaluronic acid receptor present on the hCMEC/D3 cells, were both important for the adherence of fungal particles to endothelial cells. Upon adherence of Cryptococci, the endothelial cells developed microvilli that attached to the fungi and appeared to aid in their transcytosis. Conversely, removal of hyaluronic acid or use of non-encapsulated organisms blocked adherence. The authors pointed out that although the TEER of the monolayers was low-about half that of primary brain endothelial cells-it was not further lowered by the adherence of Cryptoccocci and appeared to constitute a genuine barrier.

\section{Meningococcus}

Although meninogocci (Neisseria meningitidis) are commonly carried in the nasal and oral mucosa of humans, direct meningococcal infection of the brain, a devastating illness, is fortunately rare. How meningococci enter the brain has long been poorly understood, but hCMEC/ D3 cells used as a model of the BBB have importantly contributed to the elucidation of this mechanism. Adhesion of meningococci on hCMEC/D3 monolayers induces translocation of multiple endothelial membrane proteins, including ezrin, moesin, and actin to form honeycomb cortical plaques beneath the meningococcal colonies. Coureuil et al [57] observed that type IV pili present on pathogenic meninogocci recruited to the site of bacterial colonies the Par3/Par6/PKC larity complex. This complex normally plays a pivotal role in the establishment of eukaryotic cell polarity and governs the formation of intercellular junctions; its translocation to these cortical plaques led to the formation of ectopic intercellular junctional domains at the sites of bacteria-endothelial cell interactions and depleted junctional proteins at endothelial cell-cell interfaces. This response of hCMEC/D3 cells resulted in the opening of intercellular junctions, thus permitting paracellular bacterial infiltration across the endothelial barrier. Coureuil et al further [58] explored the hCMEC/D3 model to ascertain the signaling pathway that recruits the cortical plaques to meningococcal colony sites. They elegantly demonstrated that meningococci "hijack" another endothelial physiological pathway through activation of $\beta$-adrenergic receptors by their Type IV pili, followed by activation of the scaffolding protein $\beta$ arrestin and the tyrosine kinase Src. Activation of this pathway favors endocytosis of phosphorylated VEcadherin, a normal component of TJs, further opening up endothelial TJs. Of note, these authors recently reported that this pathway is also used by non-brain microvascular endothelial cells, but is clearly distinct from that used by epithelial cells [59].

\section{Plasmodium falciparum}

Cerebral malaria, a common complication of Plasmodium falciparum infection particularly in children, is one of the most severe and often lethal manifestations of this common tropical disease. Induction of cerebral edema during cerebral malaria is among the most feared complications of this disease, yet the mechanisms are not well understood. The hCMEC/D3 cell line has provided an excellent in vitro model for studying the detailed interactions between $P$. falciparum parasites and brain endothelium. Jambou et al [60] evaluated the mechanism of $P$. falciparum-parasitized erythrocyte adhesion to hCMEC/D3 cells and showed for the first time that this process involved trogocytosis, the transfer of membrane material from one cell (malarial antigens on parasitized erythrocyte) to another cell (endothelial cell), followed by ingestion of the entire parasitized erythrocyte. These authors compared the hCMEC/D3 cell line with the HBEC-5i cell line and showed that the HBEC5i line displayed a more activated phenotype when unstimulated, expressing much higher levels of ICAM-1, 
an important receptor in the interaction between parasitized erythrocytes and brain endothelial cells [60]. Blocking ICAM-1 or TNF $\alpha$ activation of endothelial cells prevented cytoadhesion of parasitized erythrocytes and their ingestion. More recently, hCMEC/D3 cells were used by Zougbede et al [61] to demonstrate that P. falciparum-parasitized red blood cells could alter BBB integrity also by a mechanism independent of cytoadhesion, namely, by induction of metabolic acidosis, which also resulted in opening TJs in the hCMEC/D3 monolayer, a process which also would favor development of cerebral edema.

\section{The hCMEC/D3 model for investigating neurodegenerative diseases}

It is now well recognized that brain endothelium dysfunction likely contributes to the progression of several neurodegenerative diseases, initially considered as purely due to neuronal alterations, like Alzheimer's or Parkinson's diseases. The hCMEC/D3 model has been widely used to study the toxic effects of $A \beta$ peptides on brain microvasculature in the context of Alzheimer's disease. A $\beta$ 1-40, the most abundant toxic $\mathrm{A} \beta$ peptide around blood vessels, was shown to increase hCMEC/D3 monolayer permeability, in the absence of cytotoxic effects, via the downregulation of the $\mathrm{TJ}$ protein occludin, without changing levels of claudin-5 or ZO-1 [62]. The A $\beta$ 1-40 effect on permeability could be prevented by inhibiting JNK or p38MAPK, suggesting that these signaling pathways represented a possible therapeutic target in the treatment of Alzheimer's disease.

A $\beta$ peptides have been shown to decrease the activity of efflux transporters in hCMEC/D3 cells [63]. Indeed, when hCMEC/D3 cells were exposed to A $\beta$ peptides, P-gp mRNA and protein levels decreased through down-modulation of the Wnt/ $\beta$-catenin signaling pathway (by decreasing $\beta$-catenin level and increasing DKK1 , an endogenous Wnt signaling inhibitor). These changes were reversed by administration of Wnt3a. The effect was specific for P-gp, as MDR4 and BRCP were not affected in these studies.

The hCMEC/D3 cell line was used to study cerebral amyloid angiopathy (CAA), an age-associated hemorrhagic condition commonly found in sporadic as well as some familial types of Alzheimer's disease. Fossati et al [64] observed that $A \beta$ peptides induce caspase-mediated mitochondrial dysfunction, then apoptosis in hCMEC/D3 cells; $\mathrm{A} \beta$ peptides bearing familial CAA mutations were more toxic to $C E C$ than wild type $A \beta$ peptides. Apoptosis of hCMEC/D3 cells was associated more with oligomeric peptide forms than with amyloid fibrils, a finding consistent with increasing evidence that oligomers of $A \beta$ rather than the precipitating fibers are the most neurotoxic form. Similarly, hCMEC/D3 cells were used to evaluate the contribution of metalloproteases to the pathogenesis of CAA [65]. When hCMEC/D3 were exposed to A $\beta$ peptides, the cells increased both production and enzymatic activity of MMP2 which in turn degraded $A \beta$ peptides to $A \beta$ 1-16 $\mathrm{C}$-terminal fragments resulting in decreased CEC apoptosis. Conversely, silencing MMP-2 led to further A $\beta$ 40/ 42-induced mitochondrial dysfunction and increased apoptosis of hCMEC/D3 cells. Thus, MMP2 may represent a potential vasoprotective and neuroprotective response of the brain vasculature.

Finally, the hCMEC/D3 cell line has also been used to investigate $A \beta$ clearance mechanisms from the CNS to prevent both neurotoxic and vasculotoxic effects. Indeed, a first report on hCMEC/D3 cells showing that $\mathrm{A} \beta$ is selectively effluxed when present on the luminal, but not the abluminal side [66] has been also confirmed in primary bovine CEC models [67] suggesting that P-gp may act as a protective mechanism against plasma $A \beta$ but not participate in the clearance of brain $A \beta$ although its relevance in vivo remains to be determined.

\section{Advantages and limitations of hCMEC/D3 cells}

In summary, results from various laboratories worldwide indicate that hCMEC/D3 cells retain the expression of

Table 1 Published immortalized human brain EC lines

\begin{tabular}{|c|c|c|c|c|c|c|}
\hline Cell lines & Immortalization procedure & Phenotype/limitations & $\begin{array}{l}\text { TEER } \\
\left(\Omega \cdot \mathrm{cm}^{2}\right)\end{array}$ & $\begin{array}{l}\text { LY/sucrose permeability } \\
\text { coefficient }\left(10^{-3} \mathrm{~cm} / \mathrm{min}\right)\end{array}$ & $\begin{array}{l}\text { Year } \\
\text { (first pub) }\end{array}$ & Ref. \\
\hline BB19 & HPV16 E6E7 & $\begin{array}{l}\text { Constitutive expression of VCAM-1, } \\
\text { CD36 }\end{array}$ & nd & 1.35 & 1996 & {$[68,69]$} \\
\hline HCEC & SV40T & No permeability characterization & $40 \pm 8$ & nd & 2000 & [70] \\
\hline HBEC-5i & SV40T & No expression of CD31 & $180 \pm 10$ & nd & 2006 & {$[71]$} \\
\hline NKIM-6 & HPV16 E6E7 & $\begin{array}{l}\text { No expression of claudin-5 or } \\
\text { occludin }\end{array}$ & 100 & nd & 2007 & {$[72]$} \\
\hline HBMEC-3 & SV40T & No information available & $245 \pm 8$ & nd & 2009 & {$[73]$} \\
\hline TY08 & Temperature-sensitive SV40T & Low level of functional P-gp & $37 \pm 5$ & Pe(inulin) $=1.23$ & 2010 & {$[74]$} \\
\hline $\begin{array}{l}\text { HBMEC/ } \\
\text { сi } \beta\end{array}$ & $\begin{array}{l}\text { Temperature-sensitive SV40T and } \\
\text { hTERT }\end{array}$ & Promising preliminary characterization & nd & $2.6 \pm 0.4$ & 2012 & [75] \\
\hline
\end{tabular}


most transporters and receptors expressed in vivo at the human BBB, including MDR1, BCRP, MRP4, transferrin receptor, insulin receptor, Glut-1; they also express metabolizing enzymes and TJ proteins, as expected.

Relatively few alternative models of the human BBB have been proposed, either as primary human CEC or cell lines. The following table (Table 1) summarizes other human CEC lines that have been used within the last decade. In contrast to the hCMEC/D3 cell line, most of them have been only minimally characterized. This strengthens the conclusion that the hCMEC/D3 cell line constitutes a unique model for investigating the biology of human brain endothelium.

However, a recent publication elegantly described the preparation of human BBB ECs from induced pluripotent stem (iPS) cells or embryonic stem (ES) cells [76]. Indeed, pure brain EC populations were isolated following serial incubation of human iPS or ES cells first with medium favoring neural differentiation and later with medium favoring endothelial differentiation. These stem cell-derived CECs grew as pure cultures, exhibited brain TJ molecules and transporters and developed a high TEER, significantly higher than hCMEC/D3 cells. Although the reproducibility of this sophisticated approach remains to be confirmed, these results demonstrate that understanding the molecular mechanisms of BBB development and regulation permits efficient modeling of the human BBB in vitro. This new model displays excellent barrier characteristics and may, in the future, constitute for the pharmaceutical industry a key tool for investigating BBB permeability to candidate drugs.

\section{Conclusion}

To date, the main advantage of the hCMEC/D3 cell line is that it represents a stable, easily grown and transferable population of human microvascular CEC that stably maintains a normal BBB phenotype. As illustrated above, it appears particularly well adapted for drug uptake and active transport studies, as well as for understanding the brain endothelium response to various human pathogens and inflammatory stimuli. Optimizing the TJ tightness of hCMEC/D3 cell monolayers still remains a major challenge in order to provide an in vitro model that might recapitulate all the characteristics of human BBB, encompassing permeability restriction with appropriate molecular exclusion and functional efflux and influx transport systems. As suggested above, culture under flow together with treatment with recently identified BBB modulators may greatly help design strategies for hCMEC/D3 optimization. The large network of laboratories currently working with this model worldwide actually constitutes a major asset for achieving this objective.

\section{Abbreviations}

ABC-transporters: ATP-binding cassette transporters; AJ: Adherens Junction; BBB: Blood-brain barrier; BCRP: Breast cancer resistance protein; CYP: Cytochrome P-450; CECs: Cerebral endothelial cells; CNS: Central nervous system; LiCl: Lithium chloride; LY: Lucifer yellow; MDR-1: Multidrug resistance protein-1; MRPs: Multidrug resistance-associated proteins; OGD: Oxygen and glucose deprivation; P-gp: P-glycoprotein; PPAR alpha: Peroxisome proliferator-activated receptor alpha; SLCtransporters: Solute carrier transporters; TEER: Transendothelial electrical resistance; hTERT: Catalytic subunit of human telomerase; TJ: Tight junction.

\section{Competing interests}

The authors declare that they have no conflict of interest.

\section{Authors' contributions}

BW, IAR and POC jointly analysed literature and wrote the review. All authors have read and approved the final version of the manuscript.

\section{Acknowledgements}

The authors thank F. Glacial, K. Ganeshamoorthy and C. Artus (Institut Cochin, Paris) for providing unpublished observations on hCMEC/D3 cells.

\section{Author details}

${ }^{1}$ Weill Cornell Medical College, New York, NY, USA. ${ }^{2}$ Department of Life, Health and Chemical Sciences, Open University, Milton Keynes, U.K. ${ }^{3}$ Inserm, U1016, Institut Cochin, Paris, France. ${ }^{4}$ CNRS, UMR8104, Paris, France.

${ }^{5}$ Université Paris Descartes, Sorbonne Paris Cité, Paris, France.

Received: 5 December 2012 Accepted: 25 February 2013

Published: 26 March 2013

\section{References}

1. Weksler BB, Subileau EA, Perriere N, Charneau P, Holloway K, Leveque M, Tricoire-Leignel H, Nicotra A, Bourdoulous S, Turowski P, Male DK, Roux F, Greenwood J, Romero IA, Couraud PO: Blood-brain barrier-specific properties of a human adult brain endothelial cell line. FASEB J 2005, 19:1872-1874.

2. Mkrtchyan H, Scheler S, Klein I, Fahr A, Couraud PO, Romero IA, Weksler BB, Liehr T: Molecular cytogenetic characterization of the human cerebral microvessel endothelial cell line hCMEC/D3. Cytogenet Genome Res 2009, 126:313-317.

3. Afonso PV, Ozden S, Cumont MC, Seilhean D, Cartier L, Rezaie P, Mason S, Lambert S, Huerre M, Gessain A, Couraud PO, Pique C, Ceccaldi PE, Romero IA: Alteration of blood-brain barrier integrity by retroviral infection. PLOS Pathog 2008, 14:e1000205.

4. Luissint AC, Federici C, Guillonneau F, Chrétien F, Camoin L, Glacial F, Ganeshamoorthy K, Couraud PO: Guanine nucleotide-binding protein Gai2: a new partner of claudin-5 that regulates tight junction integrity in human brain endothelial cells. J Cereb Blood Flow Metab 2012, 32:860-873.

5. Liebner S, Corada M, Bangsow T, Babbage J, Taddei A, Czupalla CJ, Reis M, Felici A, Wolburg H, Fruttiger M, Taketo MM, von Melchner $\mathrm{H}$, Plate $\mathrm{KH}$, Gerhardt H, Dejana E: Wnt/beta-catenin signaling controls development of the blood-brain barrier. J Cell Biol 2008, 183:409-417.

6. Cristante E, McArthur S, Mauro C, Maggioli E, Romero IA, Wylezinska-Arridge M, Couraud PO, Lopez-Tremoleda J, Christian HC, Weksler BB, Malaspina A, Solito E: Identification of an essential endogenous regulator of blood brain barrier integrity: pathological and therapeutic implications. Proc Natl Acad Sci USA 2013, 110:832-841.

7. Urich E, Lazic SE, Molnos J, Wells I, Freskgard PO: Transcriptional profiling of human brain endothelial cells reveals key properties crucial for predictive in vitro blood-brain barrier models. PLOS One 2012, 7:e38149.

8. Poller B, Guttmann H, Krahlenbuhl S, Weksler BB, Romero IA, Couraud PO, Tuffin G, Drewe J, Huwyler J: The human brain endothelial cell line hCMEC/D3 as a human blood-brain barrier model for drug transport studies. J Neurochem 2008, 107:1358-1368.

9. Cucullo L, Couraud PO, Weksler BB, Romero IA, Hossain M, Rapp E, Janigro D: Immortalized human brain endothelial cells and flow-based vascular modeling: a marriage of convenience for rational neurovascular studies. J Cereb Blood Flow Metab 2008, 28:312-328. 
10. Cowan SKM, Easton AS: Neutrophils block permeability increases induced by oxygen glucose deprivation in a culture model of the human bloodbrain barrier. Brain Res 2010, 1332:20-31.

11. Lopez-Ramirez MA, Fischer R, Torres-Badillo CC, Davies HA, Logan K, Pfizenmaier K, Male DK, Sharrack B, Romero IA: Role of caspases in cytokine-induced barrier breakdown in human brain endothelial cells. J Immunol 2012, 189:3130-3139.

12. Förster C, Burek M, Romero IA, Weksler BB, Couraud PO, Drenckhahn D: Differential effects of hydrocortisone and TNFalpha on tight junction proteins in an in vitro model of the human blood-brain barrier. J Physiol 2008, 586:1937-1949.

13. Haarmann A, Deiss A, Prochaska J, Foerch C, Weksler BB, Romero IA, Couraud PO, Stoll G, Rieckmann P, Buttmann M: Evaluation of soluble junctional adhesion molecule-A as a biomarker of human brain endothelial barrier breakdown. PLOS One 2010, 5:e13568.

14. Roberts TK, Eugenin EA, Lopez L, Romero IA, Weksler BB, Couraud PO, Berman JW: CCL2 disrupts the adherens junction: implications for neuroinflammation. Lab Invest 2012, 92:1213-1233.

15. Luissint AC, Artus C, Glacial F, Ganeshamoorthy K, Couraud PO: Tight junctions of the blood-brain barrier: physiological architecture and disease-associated dysregulation. Fluids Barriers CNS 2012, 9:23.

16. Butt AM, Jones HC, Abbott NJ: Electrical resistance across the blood-brain barrier in anaesthetized rats: a developmental study. J Physiol 1990, 429:47-62.

17. Hatherell K, Couraud PO, Romero IA, Weksler BB, Pilkington GJ: Development of a three-dimensional, all-human in vitro model of the blood-brain barrier using mono-, co- and tri-Transwell cultivation methods. J Neurosci Meth 2011, 199:223-229.

18. Dauchy S, Miller F, Couraud PO, Weaver RJ, Weksler BB, Romero IA, Scherrmann $J M$, De Waziers I, Decleves $X$ : Expression and transcriptional regulation of $\mathrm{ABC}$ transporters and cytochromes P450 in hCMEC/D3 human cerebral microvascular endothelial cells. Biochem Pharm 2009, 77:897-909.

19. Ohtsuki S, Ikeda C, Uchida Y, Sakamoto Y, Miller F, Glacial F, Decleves X, Scherrmann JM, Couraud PO, Kubo Y, Tachikawa M, Terasaki T: Quantitative targeted absolute proteomic analysis of transporters, receptors and junction proteins for validation of human cerebral microvascular endothelial cell line hCMEC/D3 as a human blood-brain barrier model. Mol Pharm 2012, 10:289-296.

20. Tai LM, Reddy PS, Lopez-Ramirez MA, Davies HA, Male DK, Loughlin AJ, Romero IA: Polarized P-glycoprotein expression by the immortalized human brain endothelial cell line, hCMEC/D3, restricts apical-to-basal permeability to rhodamine 123. Brain Res 2009, 1292:14-24.

21. Poller B, Drewe J, Krahlenbuhl S, Huwyler J, Guttman H: Regulation of BCRP (ABCG2) and P-glycoprotein (ABCB1) by cytokines in a model of the human blood-brain barrier. Cell Mol Neurobiol 2010, 30:63-70.

22. Male DK: Expression and induction of P-glycoprotein-1 on cultured human brain endothelium. J Cereb Blood Flow Metab 2009, 29:1760-1763.

23. Zastre JA, Chan GN, Ronaldson PT, Ramaswamy M, Couraud PO, Romero IA, Weksler B, Bendayan M, Bendayan R: Up-regulation of P-glycoprotein by HIV protease inhibitors in a human brain microvessel endothelial cell line. J Neurosci Res 2009, 87:1023-1036.

24. Zhong Y, Hennig B, Toborek M: Intact lipid rafts regulate HIV-1 Tat proteininduced activation of the Rho signaling and upregulation of P-glycoprotein in brain endothelial cells. J Cereb Blood Flow Metab 2010, 30:522-533.

25. Hoque MT, Robillard KR, Bendayan R: Regulation of breast cancer resistance protein by peroxisome proliferator-activated receptor $a$ in human brain microvessel endothelial cells. Mol Pharmacol 2012, 81:598-609.

26. Watson CP, Dogruel M, Mihoreanu L, Begley DJ, Weksler BB, Couraud PO, Romero IA, Thomas SA: The transport of nifurtimox, an anti-trypanosomal drug, in an in vitro model of the human blood-brain barrier: evidence for involvement of breast cancer resistance protein. Brain Res 2012, 1436:111-121.

27. Dickens D, Owen A, Alfirevic A, Giannoudis A, Davies A, Weksler B, Romero IA, Couraud PO, Pimohamed M: Lamotrigine is a substrate for OCT-1 in brain endothelial cells. Biochem Pharm 2012, 83:805-814.

28. Kooijmans SA, Senyschyn D, Mezhiselvam MM, Morizzi J, Charman SA, Weksler B, Romero IA, Couraud PO, Nicolazzo JA: The involvement of a $\mathrm{Na}+$ and $\mathrm{Cl}$ - -dependent transporter in the brain uptake of amantadine and rimantadine. Mol Pharm 2012, 9:883-893.

29. Carl SM, Lindley DJ, Couraud PO, Weksler BB, Romero I, Mowery SA, Knipp GT: ABC and SLC Transporter expression and Proton Oligopeptide Transporter (POT) mediated permeation across the human blood-brain barrier cell line, hCMEC/D3. Mol Pharm 2010, 7:1057-1068.
30. el-Bacha RS, Minn A: Drug metabolizing enzymes in cerebrovascular endothelial cells afford a metabolic protection to the brain. Cell Mol Biol 1999, 45:15-23.

31. Dauchy S, Dutheil F, Weaver RJ, Chassoux F, Daumas-Duport C, Couraud PO, Scherrmann JM, De Waziers I, Declèves X: ABC transporters, cytochromes P450 and their main transcription factors: expression at the human blood-brain barrier. J Neurochem 2008, 107:1518-1528.

32. Chattopadhyay N, Zastre J, Wong HL, Wu XY, Bendayan R: Solid lipid nanoparticles enhance the delivery of the HIV protease inhibitor, atanazavir, by a human brain endothelial cell line. Pharm Res 2008, 25:2262-2271.

33. Markoutsa E, Pampalakis G, Niarakis A, Romero IA, Weksler BB, Couraud PO, Antimisiaris SG: Uptake and permeability studies of BBB-targeting immunoliposomes using the hCMEC/D3 cell line. Europ J Pharmaceut Biopharmaceut 2011, 77:263-274.

34. Pinzón-Daza M, Garzón R, Couraud PO, Romero IA, Weksler BB, Ghigo D, Bosia A, Riganti C: The association of statins plus $L D L$ receptor-targeted liposome-encapsulated doxorubicin increases in vitro drug delivery across blood-brain barrier cells. Br J Pharmacol 2012, 167:1431-1447

35. Freese C, Uboldi C, Gibson MI, Unger RE, Weksler BB, Romero IA, Couraud PO, Kirkpatrick CJ: Uptake and cytotoxicity of citrate-coated gold nanospheres: comparative studies on human endothelial and epithelial cells. Part Fibre Toxicol 2012, 3:9-23

36. Li T, Bourgeois JP, Celli S, Glacial F, LeSourd AM, Mecheri S, Weksler BB, Romero IA, Couraud PO, Rougeon F, Lafaye P: Cell-penetrating anti-GFAP $\mathrm{VHH}$ and corresponding fluorescent fusion protein VHH-GFP spontaneously cross the blood-brain barrier and specifically recognize astrocytes: application to brain imaging. FASEB J 2012, 26:3969-3979.

37. Lopez-Ramirez MA, Fischer R, Torres-Badillo CC, Davies HA, Logan K, Pfizenmaier K, Male DK, Sharrack B, Romero IA: Role of caspases in cytokine-induced barrier breakdown in human brain endothelial cells. J Immunol 2012, 189:3130-3139.

38. Fasler-Kan E, Suenderhauf C, Barteneva N, Poller B, Gygax D, Huwyler J: Cytokine signaling in the human brain capillary endothelial cell line hCMEC/D3. Brain Res 2010, 1354:15-22.

39. Subileau EA, Rezaie P, Davies HA, Colyer FM, Greenwood J, Male DK, Romero IA: Expression of chemokines and their receptors by human brain endothelium: implications for multiple sclerosis. J Neuropathol Exp Neurol 2009, 68:227-240.

40. Hurst LA, Bunning RA, Couraud PO, Romero IA, Weksler BB, Sharrack B, Woodroofe MN: Expression of ADAM-17, TIMP-3 and fractalkine in the human adult brain endothelial cell line, hCMEC/D3, following proinflammatory cytokine treatment. J Neuroimmunol 2009, 210:108-112.

41. Reijerkerk A, Kooij G, van der Pol SM, Leyen T, van Het Hof B, Couraud PO, Vivien D, Dijkstra CD, de Vries HE: Tissue-type plasminogen activator is a regulator of monocyte diapedesis through the brain endothelial barrier. J Immunol 2008, 181:3567-3574.

42. van Doorn R, Lopes Pinheiro MA, Kooij G, Lakeman K, van Het Hof B, van der Pol SM, Geerts D, van Horssen J, van der Valk P, van der Kam E, Ronken E, Reijerkerk A, de Vries HE: Sphingosine 1-phosphate receptor 5 mediates the immune quiescence of the human brain endothelial barrier. J Neuroinflammation 2012, 9:133.

43. Viegas $P$, Chaverot $N$, Enslen $H$, Perrière $N$, Couraud $P O$, Cazaubon S: Junctional expression of the prion protein PrPc by brain endothelial cells: a role in trans-endothelial migration of human monocytes. $J \mathrm{Cell} \mathrm{Sci}$ 2006, 119:4634-4643.

44. Bahbouhi B, Berthelot L, Pettre S, Michel L, Wiertlewski S, Weksler BB, Romero IA, Miller F, Couraud PO, Brouard S, Laplaud DA, Soulillou JP: Peripheral blood CD4+ T lymphocytes from multiple sclerosis patients are characterized by higher PSGL-1 expression and transmigration capacity across a human blood-brain barrier-derived endothelial cell line. J Leukocyte Biol 2008, 86:1049-1059.

45. Joice SL, Mydeen F, Couraud PO, Weksler BB, Romero IA, Fraser PA, Easton AS: Modulation of blood-brain barrier permeability by neutrophils: in vitro and in vivo studies. Brain Res 2009, 1298:13-23.

46. Afonso PV, Ozden S, Prevost MC, Schmitt C, Seilhean D, Weksler B, Couraud PO, Gessain A, Romero IA, Ceccaldi PE: Human blood-brain barrier disruption by retroviral-infected lymphocytes: role of myosine light chain kinase in endothelial tight-junction disorganization. J Immunol 2007, 179:2576-2583.

47. András IE, Toborek M: HIV-1-induced alterations of claudin-5 expression at the blood-brain barrier level. Meth Mol Biol 2011, 762:355-370. 
48. Zhong Y, Zhang B, Eum SY, Toborek M: HIV-1 Tat triggers nuclear localization of ZO-1 via Rho signaling and CAMP response elementbinding protein activation. J Neurosci 2012, 32:143-150.

49. Andras JE, Rha G, Huang W, Eum S, Couraud PO, Romero IA, Hennig B, Toborek M: Simvastatin protects against amyloid beta and HIV-1 Tatinduced promoter activities of inflammatory genes in brain endothelial cells. Mol Pharmacol 2008, 273:1424-1433.

50. Huang W, Rha GB, Han MJ, Eum SY, András IE, Zhong Y, Hennig B, Toborek M: PPARalpha and PPARgamma effectively protect against HIV-induced inflammatory responses in brain endothelial cells. J Neurochem 2008 , 107:497-509.

51. Huang W, Eum SY, András IE, Hennig B, Toborek M: PPARalpha and PPARgamma attenuate HIV-induced dysregulation of tight junction proteins by modulations of matrix metalloproteinase and proteasome activities. FASEB J 2009, 23:1596-1606.

52. Huang W, Rha GB, Chen L, Seelbach MJ, Zhang B, András IE, Bruemmer D, Hennig B, Toborek M: Inhibition of telomerase activity alters tight junction protein expression and induces transendothelial migration of HIV-1-infected cells. Am J Physiol Heart Circ Physiol 2010, 298:1136-1145.

53. Andras IE, Eum SY, Huang W, Zhong Y, Hennig B, Toborek M: HIV-1induced amyloid beta accumulation in brain endothelial cells is attenuated by simvastatin. Mol Cell Neurosci 2010, 43:232-234.

54. Zhong Y, Smart EJ, Weksler BB, Coutraud PO, Hennig B, Toborek M: Caveolin-1 regulates human immunodeficiency virus-1 Tat-induced alterations of tight junction protein expression via modulation of the Ras signaling. J Neurosci 2008, 28:7788-7796.

55. András IE, Eum SY, Toborek M: Lipid rafts and functional caveolae regulate HIV-induced amyloid beta accumulation in brain endothelial cells. Biochem Biophys Res Commun 2012, 421:177-183.

56. Vu K, Weksler BB, Romero IA, Couraud PO, Gelli A: Immortalized human brain endothelial cell line hCMEC/D3 as a model of the blood-brain barrier facilitates in vitro studies of central nervous system infection by Cryptococcus neoformans. Eukaryot Cell 2009, 8:1803-1811.

57. Coureuil M, Mikaty G, Miller F, Lecuyer H, Bernard S, Bourdoulous S, Dumeni G, Mege RM, Weksler BB, Romero IA, Couraud PO, Nassif X: Meningococcal type IV pili recruit the polarity complex to cross the brain endothelium. Science 2009, 325:83-87.

58. Coureuil M, Lécuyer H, Scott MG, Boularan C, Enslen H, Soyer M, Mikaty G, Bourdoulous S, Nassif X, Marullo S: Meningococcus hijacks a $\beta 2-$ adrenoceptor/ $\beta$-Arrestin pathway to cross brain microvasculature endothelium. Cell 2010, 143:1149-1160.

59. Lécuyer $H$, Nassif $X$, Coureuil M: Two strikingly different signaling pathways are induced by meningococcal type IV pili on endothelial and epithelial cells. Infect Immun 2012, 80:175-186.

60. Jambou R, Combes V, Jambou MJ, Weksler BB, Couraud PO, Grau GE: Plasmodium falciparum adhesion on human brain microvascular endothelial cells involves transmigration-like cup formation and induces opening of intercellular junctions. PLoS Pathog 2010, 6:e1001021.

61. Zougbede S, Miller F, Ravassard P, Rebollo A, Cicron L, Couraud PO, Mazier D, Moreno A: Metabolic acidosis induced by Plasmodium falciparum intraerythrocytic stages alters blood-brain barrier integrity. J Cereb Blood Flow Metab 2011, 31:514-526.

62. Tai LM, Holloway KA, Male DK, Loughlin AJ, Romero IA: Amyloid-beta-induced occludin down-regulation and increased permeability in human brain endothelial cells is mediated by MAPK activation. J Cell Mol Med 2010, 14:1101-1112.

63. Kania KD, Wijesuriya HC, Hladky SB, Barrand MA: Beta amyloid effects on expression of multidrug efflux transporters in brain endothelial cells. Brain Res 2011, 1418:1-11.

64. Fossati S, Cam J, Mezhericher E, Romero IA, Couraud PO, Weksler BB, Ghiso J, Rostagno A: Differential activation of mitochondrial apoptotic pathways by vasculotropic amyloid beta variants in cells composing thee cerebral vessel walls. FASEB J 2010, 24:229-241.

65. Hernandez-Guillamon M, Mawhirt S, Fossati S, Blais S, Pares M, Penalba A, Boada M, Couraud PO, Neubert TA, Montaner J, Ghiso J, Rostagno A: Matrix metalloproteinase 2 (MMP-2) degrades soluble vasculotropic amyloidbeta $\mathrm{E} 22 \mathrm{Q}$ and L34V mutants, delaying their toxicity for human brain microvascular endothelial cells. J Biol Chem 2010, 285:27144-27158.

66. Tai LM, Loughlin AJ, Male DK, Romero IA: P-glycoprotein and breast cancer resistance protein restrict apical-to-basolateral permeability of human brain endothelium to amyloid-beta. J Cereb Blood Flow Metab 2009, 29:1079-1083.
67. Candela P, Gosselet F, Saint-Pol J, Sevin E, Boucau MC, Boulanger E, Cecchelli R, Fenart L: Apical-to-basolateral transport of amyloid- $\beta$ peptides through blood-brain barrier cells is mediated by the receptor for advanced glycation end-products and is restricted by P-glycoprotein. J Alzheimers Dis 2010, 22:849-859.

68. Prudhomme JG, Sherman IW, Land KM, Moses AV, Stenglein S, Nelson JA: Studies of Plasmodium falciparum cytoadherence using immortalized human brain capillary endothelial cells. Int J Parasitol 1996, 26:647-655.

69. Kusch-Poddar M, Drewe J, Fux I, Gutmann H: Evaluation of the immortalized human brain capillary endothelial cell line BB19 as a human cell culture model for the blood-brain barrier. Brain Res 2005, 1064:21-31.

70. Kannan R, Chakrabarti R, Tang D, Kim KJ, Kaplowitz N: GSH transport in human cerebrovascular endothelial cells and human astrocytes: evidence for luminal localization of $\mathrm{Na}$--dependent GSH transport in HCEC. Brain Res 2000, 852:374-382.

71. Wassmer SC, Combes V, Candal FJ, Juhan-Vaque I, Grau GE: Platelets potentiate brain endothelial alterations induced by Plasmodium falciparum. Infect Immun 2006, 74:645-653.

72. Ketabi-Kiyanvash N, Herold-Mende C, Kashfi F, Caldeira S, Tommasino M, Haefeli WE, Weiss J: NKIM-6, a new immortalized human brain capillary endothelial cell line with conserved endothelial characteristics. Cell Tissue Res 2007, 328:319-329.

73. Chaitanya GV, Cromer WE, Wells SR, Jennings MH, Couraud PO, Romero IA Weksler BB, Erdreich-Epstein A, Mathis HM, Minagar A, Alexander S: Gliovascular and cytokine interactions moderate brain endothelial barrier in vitro. J Neuroinflammation 2009, 8:162.

74. Sano Y, Shimizu F, Abe M, Maeda T, Kashiwamura Y, Ohtsuki S, Terasaki T, Obinala M, Kaijwara K, Fujii M, Suzuki M, Kanda T: Establishment of a new conditionally immortalized human brain microvascular endothelial cell line retaining an in vivo blood-brain barrier function. J Cell Physio/ 2010, 225:519-528.

75. Kamiichi A, Furihata T, Kishida S, Ohta Y, Saito K, Kawamatsu S, Chiba K: Establishment of a new conditionally immortalized cell line from human brain microvascular endothelial cells: a promising tool for human blood-brain barrier studies. Brain Res 2012, 1488:113-122.

76. Lippmann ES, Azarin SM, Kay JE, Nessler RA, Wilson HK, Al-Ahmad A, Palecek SP, Shusta EV: Derivation of blood-brain barrier endothelial cells from human pluripotent stem cells. Nat Biotech 2012, 30:783-791.

\section{doi:10.1186/2045-8118-10-16}

Cite this article as: Weksler et al:: The hCMEC/D3 cell line as a model of the human blood brain barrier. Fluids and Barriers of the CNS 2013 10:16.

\section{Submit your next manuscript to BioMed Central and take full advantage of:}

- Convenient online submission

- Thorough peer review

- No space constraints or color figure charges

- Immediate publication on acceptance

- Inclusion in PubMed, CAS, Scopus and Google Scholar

- Research which is freely available for redistribution 